\title{
Preparation of Ginsenoside $\mathrm{Rg} 3$ and Protection against $\mathrm{H}_{2} \mathrm{O}_{2}$-Induced Oxidative Stress in Human Neuroblastoma SK-N-SH Cells
}

\author{
Gang Li, ${ }^{1}$ Xiao-xiao Zhang, ${ }^{1}$ Lin Lin, ${ }^{1}$ Xiao-ning Liu, ${ }^{1}$ Cheng-jun Ma, \\ Ji Li, ${ }^{1}$ and Chi-bo Wang ${ }^{2}$ \\ ${ }^{1}$ Life School of Yantai University, Yantai, Shandong 264005, China \\ ${ }^{2}$ Department of Neurosurgery, Yantaishan Hospital, Yantai, Shandong 264000, China
}

Correspondence should be addressed to Chi-bo Wang; wangcbyt@sohu.com

Received 16 May 2014; Accepted 30 May 2014; Published 18 June 2014

Academic Editor: Wang Chunming

Copyright @ 2014 Gang Li et al. This is an open access article distributed under the Creative Commons Attribution License, which permits unrestricted use, distribution, and reproduction in any medium, provided the original work is properly cited.

\begin{abstract}
The aim of this study is to evaluate the protection of ginsenoside Rg3 against oxidative stress in human neuroblastoma SK-NSH cells. 20(R)-ginsenoside Rg3 (20(R)-Rg3) and 20(S)-ginsenoside Rg3 (20(S)-Rg3) were prepared by the method of chemical degradation and column chromatography, and the structure of the two compounds was characterized by ${ }^{1} \mathrm{H}-\mathrm{NMR}$ and ${ }^{13} \mathrm{C}-\mathrm{NMR}$ spectroscopy. MTT assay and LDH leakage assay were used to determine the cell viability and the oxidative stress cellular model was established by means of $\mathrm{H}_{2} \mathrm{O}_{2}(600 \mu \mathrm{M}$ for $4 \mathrm{~h})$. We also investigated the changes of intracellular MDA content, SOD activity, and ROS formation after the treatment of ginsenoside $\mathrm{Rg} 3$ for $20 \mathrm{~h}$. The results indicated that both 20 (R)-Rg3 and 20 (S)-Rg3 had obvious protection against $\mathrm{H}_{2} \mathrm{O}_{2}$-induced oxidative stress in SK-N-SH cells. Moreover, 20(R)- $\mathrm{Rg} 3$ exhibited better antioxidant activity than 20(S)-Rg3 in vitro. These findings are expected to provide some implication for further research and application of ginsenoside Rg3 in neuroprotection.
\end{abstract}

\section{Introduction}

Panax ginseng is known to have various pharmacological activities [1]. Among several products of ginseng, ginsenosides are the main components and have been proved to possess many bioactivities, which mostly including antioxidation, neuroprotection, and anticancer [2].

Ginsenoside Rg3, a saponin extracted from ginseng, had been recently reported to protect the neuronal cells and animals with neurological injuries [3-6]. Ginsenoside Rg3 exists as stereoisomer of 20(R)- or 20(S)-form (Figure 1) and with different bioactivity $[7,8]$. The two compounds can be biotransformed by human intestinal bacteria $[9,10]$. In recent years, researchers have found the protection of different Rg3 isomer on nervous system. Tian et al. have investigated the neuroprotective effects of 20 (S)-Rg3 on focal cerebral ischemia in rats and found that $20(\mathrm{~S})-\mathrm{Rg} 3$ could inhibit the opening of mitochondrial permeability transition pore by free radical scavenging action in the rats brain $[11,12]$.
He et al. have investigated the neuroprotective effect of 20 (R)Rg3 against transient focal cerebral ischemia in male SpragueDawley rats and finally indicated its neuroprotective effect may be involved in the downregulation of calpain I and caspase-3 [13]. However, rare reports have been found on the comparison study of 20 (R)-Rg3 and 20 (S)-Rg3, especially in the study of antioxidant and neural protection.

In the present study, we prepared the stereoisomer of 20(R)-Rg3 and 20(S)-Rg3 by chemical conversion method and characterized the structure by ${ }^{1} \mathrm{H}-\mathrm{NMR}$ and ${ }^{13} \mathrm{C}-$ NMR spectroscopy. Human neuroblastoma SK-N-SH cells are often used as in vitro models of neuronal function and differentiation $[14,15]$. Here, we established the oxidative stress model by using SK-N-SH cells exposed to $\mathrm{H}_{2} \mathrm{O}_{2}$, and the protection of ginsenoside $\mathrm{Rg} 3$ against $\mathrm{H}_{2} \mathrm{O}_{2}$-induced oxidative stress was evaluated by the measurement of lactate dehydrogenase (LDH) release, malondialdehyde (MDA) content, superoxide dismutase (SOD) activity, and intracellular reactive oxygen species (ROS) level. Some implication is 


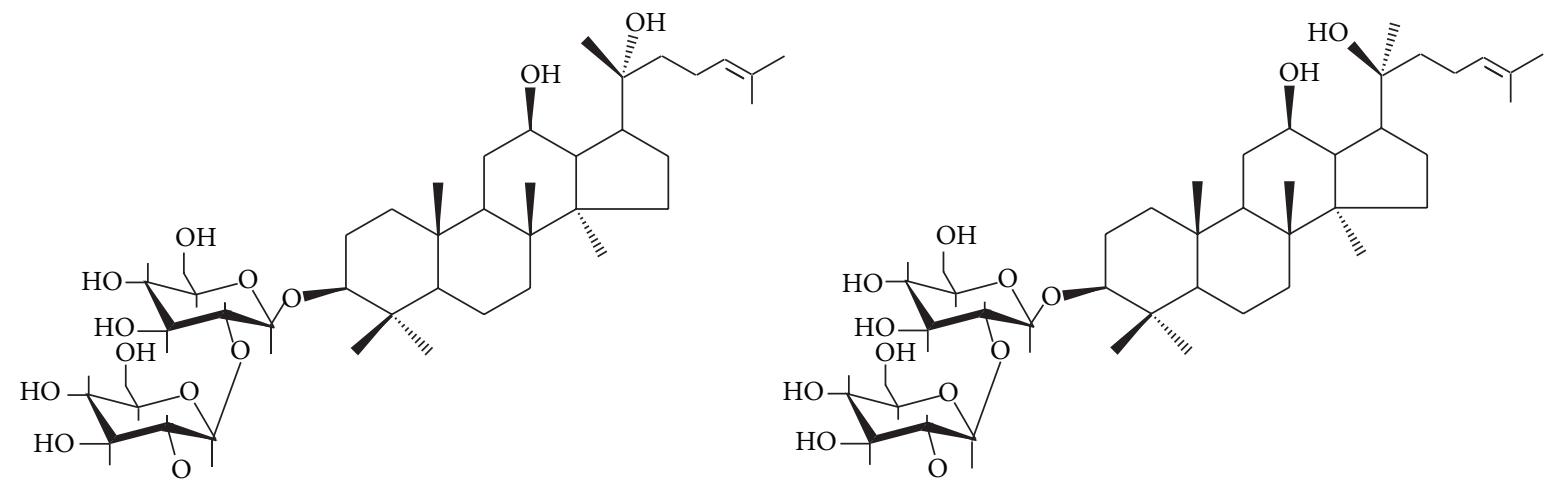

FIgURE 1: Structural formulas of 20(R)-Rg3 and 20(S)-Rg3.

expected to be provided for the further research and application of ginsenoside $\mathrm{Rg} 3$ in neuroprotection through this study.

\section{Materials and Methods}

2.1. Cells and Chemicals. Human neuroblastoma SK-N-SH cells were obtained from the cell bank of the Institute of Biochemistry and Cell Biology in Shanghai, China. Phosphate buffered saline (PBS), MEM medium, fetal bovine serum (FBS), penicillin-streptomycin solution, and Trypsin-EDTA solution were purchased from GIBCO Corporation (Beijing Representative Office, China). Ginseng stem-leave saponins (GSLS) were bought from Hongjiu Biological Technology Co., Ltd, in Jilin, China. Other chemical reagents were analytically pure and were purchased from Sinopharm Chemical Reagent Co., Ltd, Shanghai, China.

2.2. Preparation of Ginsenoside Rg3. $20 \mathrm{~g}$ of GSLS was dissolved with $500 \mathrm{~mL}$ of acetic acid water (30:70) and extracted under reflux at $90^{\circ} \mathrm{C}$ for $1 \mathrm{~h}$. The extraction mixture was then filtered. The residue was washed using ethanol and recrystallized from methanol water. Finally, $1.48 \mathrm{~g}$ target compound was obtained. The structure of the compound was confirmed by ${ }^{1} \mathrm{H}-\mathrm{NMR}$ and ${ }^{13} \mathrm{C}-\mathrm{NMR}$ as $20(\mathrm{R})-$ ginsenoside Rg3 (20(R)-Rg3), 20(R)-protopanaxadiol-3-Obeta-D-glucopyranosyl $(1 \rightarrow 2)$-beta-D-glucopyranoside.

$20 \mathrm{~g}$ of GSLS was mixed with $1000 \mathrm{~mL}$ of glycerin and $100 \mathrm{~g}$ of sodium hydroxide and reacted at $210^{\circ} \mathrm{C}$ for $2 \mathrm{~h}$. As the solution cooled, $\mathrm{pH}$ was adjusted to 7.4. Then the precipitation was concentrated to dryness in vacuum and $7.7 \mathrm{~g}$ of gray degradation was obtained. Then, the degradation underwent silica gel column chromatography and was eluted with ethyl acetate: methanol $(8: 2)$. The resulting eluate was combined into two fractions (Fr1 and Fr2) based on the silica gel TLC profiles of each tube. The Fr2 was then purified again with chloroform:methanol $(7: 3)$. The final compound was recrystallized with methanol and confirmed by ${ }^{1} \mathrm{H}-\mathrm{NMR}$ and ${ }^{13} \mathrm{C}-\mathrm{NMR}$ as $20(\mathrm{~S})$ ginsenoside Rg3 (20(S)-Rg3), 20(S)-protopanaxadiol-3-Obeta-D-glucopyranosyl $(1 \rightarrow 2)$-beta-D-glucopyranoside.
2.3. Cell Culture. Human neuroblastoma SK-N-SH cells were cultured in MEM medium that contained 10\% FBS, $100 \mathrm{U} / \mathrm{mL}$ penicillin, and $100 \mu \mathrm{g} / \mathrm{mL}$ streptomycin at $37^{\circ} \mathrm{C}$ in a humidified atmosphere containing $5 \% \mathrm{CO}_{2}$. Cells were seeded on Petri dishes $(10 \mathrm{~cm})$ and the medium was replaced every other day.

2.4. Cell Viability Assay. The cytotoxicity of ginsenoside $\mathrm{Rg} 3$ was detected by MTT assay. The oxidative damage of $\mathrm{H}_{2} \mathrm{O}_{2}$ to SK-N-SH cells was confirmed by measuring the release of the cytosolic enzyme LDH to the culture medium. And the protective effect of ginsenoside $\mathrm{Rg} 3$ against toxicity of $\mathrm{H}_{2} \mathrm{O}_{2}$ was also confirmed by both MTT assay and LDH assay.

2.4.1. MTT Assay. The cytotoxicity of ginsenoside $\mathrm{Rg} 3$ was determined by the MTT assay as described [16]. SK-N-SH cells were plated in triplicate at a density of $1 \times 10^{4}$ cells/well in 96-well plates for $24 \mathrm{~h}$. The culture media were aspirated and replaced with fresh culture media containing various concentrations of $20(\mathrm{R})-\mathrm{Rg} 3$ or $20(\mathrm{~S})-\mathrm{Rg} 3(1.5 \sim 200 \mu \mathrm{g} / \mathrm{mL})$ for $20 \mathrm{~h}$. Then, $10 \mu \mathrm{L}$ MTT solution $(5 \mathrm{mg} / \mathrm{mL})$ was added into each well for further $4 \mathrm{~h}$ at $37^{\circ} \mathrm{C}$. And $150 \mu \mathrm{L}$ of DMSO was added in order to dissolve the formazan crystals. The UV absorbance of the solubilized formazan crystals was measured by microplate reader (Spectra MR, Dynex) at 490 nm. Cell viability (\%) was calculated.

2.4.2. LDH Assay. The leakage of $\mathrm{LDH}$ was measured by using a colorimetric LDH assay kit (Nanjing Jiancheng Bioengineering Institute, Nanjing, China) according to the manufacturer's instructions. Briefly, $1 \times 10^{4}$ cells/well were cultured in 96 well plates overnight. Then, the cells were treated with various concentration of $\mathrm{H}_{2} \mathrm{O}_{2}(200,400,600$, $800,1000$, and $1200 \mu \mathrm{M})$ for different time $(2 \mathrm{~h}, 4 \mathrm{~h}$, and $6 \mathrm{~h})$. Then, $20 \mu \mathrm{L}$ of cell medium was added into basic solution to measure extracellular LDH activity, which could catalyze the conversion of lactate to pyruvate and react with 2,4-dinitrophenylhydrazine to give the brownish red color [17]. The absorbance was measured at $450 \mathrm{~nm}$ by automatic microplate reader.

As for the protective effect of ginsenoside Rg3, SK-N$\mathrm{SH}$ cells were preincubated with $20(\mathrm{R})-\mathrm{Rg} 3$ or $20(\mathrm{~S})-\mathrm{Rg} 3$ 
(10, $20 \mu \mathrm{g} / \mathrm{mL})$ for $24 \mathrm{~h}$ before $\mathrm{H}_{2} \mathrm{O}_{2}$ oxidative damage, and the detection of $\mathrm{LDH}$ released into the culture medium was completed with the same process.

2.5. Oxidative Stress Analysis. After pretreatment with 20(R)$\mathrm{Rg} 3$ or $20(\mathrm{~S})-\mathrm{Rg} 3$ for $24 \mathrm{~h}$ and subsequent treatment with $600 \mu \mathrm{M} \mathrm{H} \mathrm{H}_{2} \mathrm{O}_{2}$ for $4 \mathrm{~h}, \mathrm{H}_{2} \mathrm{O}_{2}$-induced oxidative stress and the protection of ginsenoside $\mathrm{Rg} 3$ were analyzed by cytosolic superoxide dismutase (SOD) assay, extracellular malondialdehyde (MDA) assay, and intracellular reactive oxygen species (ROS) detection.

2.5.1. SOD and MDA Determination. After treatment with ginsenoside $\mathrm{Rg} 3$ and $\mathrm{H}_{2} \mathrm{O}_{2}$, the culture supernatant was collected, and MDA contents were measured using a spectrometer at $586 \mathrm{~nm}$ according to the manufacturer of the assay kit (Nanjing Jiancheng Bioengineering Institute, Nanjing, China). Then, the cells were detached with $0.25 \%$ trypsin and centrifuged at $1200 \mathrm{rpm}$. SOD activities were analyzed according to the instruction of the assay kits (Nanjing Jiancheng Bioengineering Institute, Nanjing, China) at $550 \mathrm{~nm}$.

2.5.2. Detection of Intracellular ROS. ROS production in SK$\mathrm{N}$-SH cells was measured using the redox-sensitive fluorescent dye DCFH-DA (Jiamei Biotechnology Co., Ltd., Beijing, China). After treatment with ginsenoside $\mathrm{Rg} 3$ and $\mathrm{H}_{2} \mathrm{O}_{2}$, cells were incubated with $25 \mu \mathrm{M}$ DCFH-DA for $20 \mathrm{~min}$. The cells were detached with $0.25 \%$ trypsin and centrifuged at $1200 \mathrm{rpm}$. Then, the cells were rinsed twice with phenolred-free MEM containing 1\% FBS, and fluorescence was detected on automatic microplate reader $(488 \mathrm{~nm}$ excitation and $520 \mathrm{~nm}$ emission). The mean fluorescent signals for 10,000 cells were recorded and the relative intracellular ROS level (\%) was calculated.

2.6. Statistical Analyses. Data were expressed as mean \pm S.D., and differences were evaluated using unpaired Student's $t$ tests or ANOVA by SPSS 18.0 software. The level of statistical significance was set at $P<0.05$.

\section{Results and Discussion}

3.1. Chemical Structure Identification. The structural identification of ginsenoside $\mathrm{Rg} 3$ was carried out by electrospray ionization mass spectrometry (ESI-MS), ${ }^{1} \mathrm{H}$ NMR, and ${ }^{13} \mathrm{C}$ NMR spectra as follows.

20(R)-Rg3: ${ }^{1} \mathrm{H}-\mathrm{NMR}\left(400 \mathrm{~Hz}, \mathrm{C}_{5} \mathrm{D}_{5} \mathrm{~N}\right), \delta: 0.83(3 \mathrm{H}, \mathrm{S}$, $\left.\mathrm{CH}_{3}-29\right), 1.01\left(3 \mathrm{H}, \mathrm{S}, \mathrm{CH}_{3}-30\right), 0.96\left(3 \mathrm{H}, \mathrm{S}, \mathrm{CH}_{3}-19\right), 1.12$ $\left(3 \mathrm{H}, \mathrm{S}, \mathrm{CH}_{3}-18\right), 1.30\left(3 \mathrm{H}, \mathrm{S}, \mathrm{CH}_{3}-28\right), 1.66\left(3 \mathrm{H}, \mathrm{S}, \mathrm{CH}_{3}-27\right)$, $1.70\left(3 \mathrm{H}, \mathrm{S}, \mathrm{CH}_{3}-26\right), 4.63(1 \mathrm{H}, \mathrm{d}, J=7.4 \mathrm{~Hz}), 5.31(1 \mathrm{H}, \mathrm{d}$, $J=7.4 \mathrm{~Hz}) ;{ }^{13} \mathrm{C}-\mathrm{NMR}\left(400 \mathrm{~Hz}, \mathrm{C}_{5} \mathrm{D}_{5} \mathrm{~N}\right), \delta: 39.1(\mathrm{C}-1), 26.7$ (C-2), 88.9 (C-3), 39.9 (C-4), 56.3 (C-5), 18.4 (C-6), 35.1 (C7), 36.9 (C-8), 50.6 (C-9), 39.7 (C-10), 32.2 (C-11), 70.9 (C12), 49.2 (C-13), 51.7 (C-14), 31.4 (C-15), 28.1 (C-16), 50.4 (C17), 16.6 (C-18), 72.9 (C-19), 22.8 (C-20), 43.3 (C-21), 22.6 (C22), 126.0 (C-23), 130.8 (C-24), 25.8 (C-25), 17.7 (C-26), 26.6 (C-27), 15.8 (C-28), 17.3 (C-29), 105.1 (C-30), 83.5 (C-31), 71.6

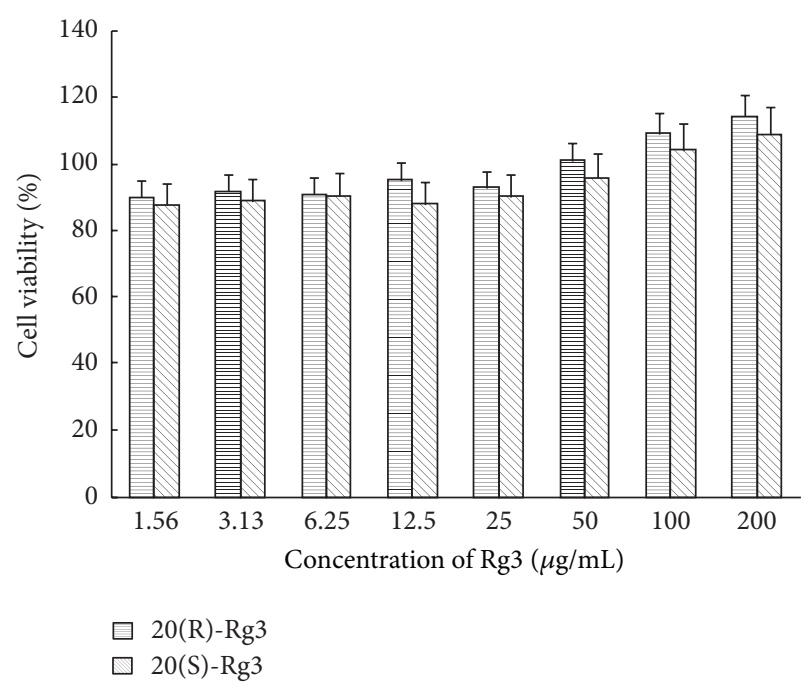

FIGURE 2: Cytotoxicity effects of ginsenoside Rg3 on SK-N-SH cells.

(C-32), 77.9 (C-33), 62.6 (C-34), 106.1 (C-35), 77.1 (C-36), 78.3

(C-37), 71.6 (C-38), 78.1 (C-39), 62.8 (C-40).

20(S)-Rg3: ${ }^{1} \mathrm{H}-\mathrm{NMR}\left(400 \mathrm{~Hz}, \mathrm{C}_{5} \mathrm{D}_{5} \mathrm{~N}\right), \delta: 0.80(3 \mathrm{H}, \mathrm{S}$, $\left.\mathrm{CH}_{3}-29\right), 0.95\left(3 \mathrm{H}, \mathrm{S}, \mathrm{CH}_{3}-30\right), 0.96\left(3 \mathrm{H}, \mathrm{S}, \mathrm{CH}_{3}-19\right), 1.11$ $\left(3 \mathrm{H}, \mathrm{S}, \mathrm{CH}_{3}-18\right), 1.30\left(3 \mathrm{H}, \mathrm{S}, \mathrm{CH}_{3}-28\right), 1.61\left(3 \mathrm{H}, \mathrm{S}, \mathrm{CH}_{3}-27\right)$, $1.65\left(3 \mathrm{H}, \mathrm{S}, \mathrm{CH}_{3}-26\right), 4.83(1 \mathrm{H}, \mathrm{d}, J=7.6 \mathrm{~Hz}), 5.29(1 \mathrm{H}, \mathrm{d}$, $J=7.2 \mathrm{~Hz}) ;{ }^{13} \mathrm{C}-\mathrm{NMR}\left(400 \mathrm{~Hz}, \mathrm{C}_{5} \mathrm{D}_{5} \mathrm{~N}\right), \delta: 39.1(\mathrm{C}-1), 27.0$ (C-2), 88.9 (C-3), 39.9 (C-4), 56.3 (C-5), 18.4 (C-6), 35.8 (C7), 36.9 (C-8), 32.0 (C-9), 71.6 (C-10), 48.5 (C-11), 51.7 (C-12), 39.7 (C-13), 32.0 (C-14), 71.6 (C-15), 48.5 (C-16), 51.7 (C-17), 32.0 (C-18), 26.8 (C-19), 35.1 (C-20), 23.0 (C-21), 126.3 (C-22), 130.7 (C-23), 25.8 (C-24), 17.6 (C-25), 28.1 (C-26), 16.3 (C-27), 17.0 (C-28), 105.1 (C-29), 83.4 (C-30), 78.3 (C-31), 71.6 (C-32), 77.2 (C-33), 62.7 (C-34), 105.1 (C-35), 77.1 (C-36), 78.3 (C-37), 72.8 (C-38), 77.9 (C-39), 62.8 (C-40).

3.2. Cell Viability Assay. As showed in Figure 2, both 20(R)$\mathrm{Rg} 3$ and 20(S)-Rg3 had no obvious cytotoxicity on SK-N-SH cells when the concentration was $1.5 \sim 200 \mu \mathrm{g} / \mathrm{mL}$. Intracellular LDH assay has proved that $\mathrm{H}_{2} \mathrm{O}_{2}$ could significantly lead to cell damage along with the extension of the time and with the increase of the concentration (Figure 3). After incubated with $\mathrm{H}_{2} \mathrm{O}_{2}$, SK-N-SH cells were also found with different changes in shape through inverted microscope observation. Some cells were swelled, shrunken, and unevenly distributed. The cellular edge became unclear and even fell off when the damage was serious.

3.3. Protection of $\mathrm{Rg} 3$ against $\mathrm{H}_{2} \mathrm{O}_{2}$-Induced Oxidative Stress. The results from MTT assay and intracellular LDH analysis had suggested that $\mathrm{H}_{2} \mathrm{O}_{2}$-induced oxidative stress could lead to significant cell death. And previous ginsenoside Rg3 treatment was able to increase the cell survival rate and vitality with a dose-dependent manner (shown in Figures 4 and 5). Furthermore, the protective activity of 20(R)-Rg3 was significantly better than that of $20(S)-\operatorname{Rg} 3(P<0.05)$. 


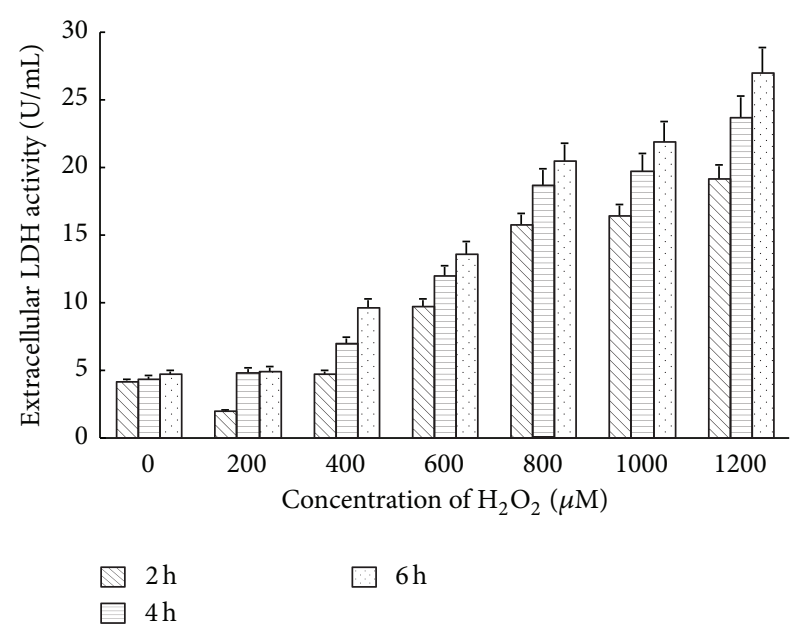

FIGURE 3: Effect of $\mathrm{H}_{2} \mathrm{O}_{2}$ on leakage of LDH in SK-N-SH cells.

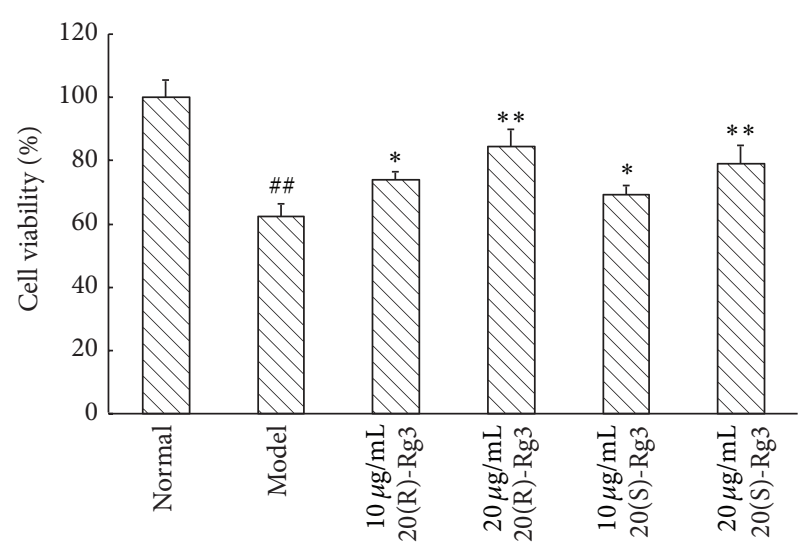

FIGURE 4: Protective effect of ginsenoside Rg3 on SK-N-SH cells by MTT assay. ${ }^{\# \#} P<0.01$ versus normal group, ${ }^{*} P<0.05$, and ${ }^{* *} P<$ 0.01 versus model group.

MDA produced in cytoplasm was determined as a common indicator of lipid peroxidation [18]. $\mathrm{H}_{2} \mathrm{O}_{2}(600 \mu \mathrm{M}$ for $4 \mathrm{~h}$ ) could significantly increase the production of MDA generated in SK-N-SH cells. However, 20(R)-Rg3 and 20(S)$\mathrm{Rg} 3$ could effectively reduce the content of MDA as showed in Figure 6.

SOD is an effective defense enzyme that catalyses the dismutation of superoxide anions into hydrogen peroxide [19]. Our results in the present study showed that the antioxidantive activity of intracellular SOD was significantly decreased in $\mathrm{H}_{2} \mathrm{O}_{2}$ toxic groups compared with the normal cells $(P<0.01)$, which implied increased oxidative damage to the cells. On the contrary, SOD levels were significantly elevated by incubation of $20(\mathrm{R})-\mathrm{Rg} 3$ and $20(\mathrm{~S})-\mathrm{Rg} 3$. These results demonstrated that the antioxidant ability of ginsenoside Rg3 was very critical for its protection on SK-NSH cells. In addition, the protective effects of 20(R)-Rg3 were remarkable and powerful than that of $20(S)-\mathrm{Rg} 3$ at the concentration of $20 \mu \mathrm{g} / \mathrm{mL}(P<0.05)$ (Figure 7).

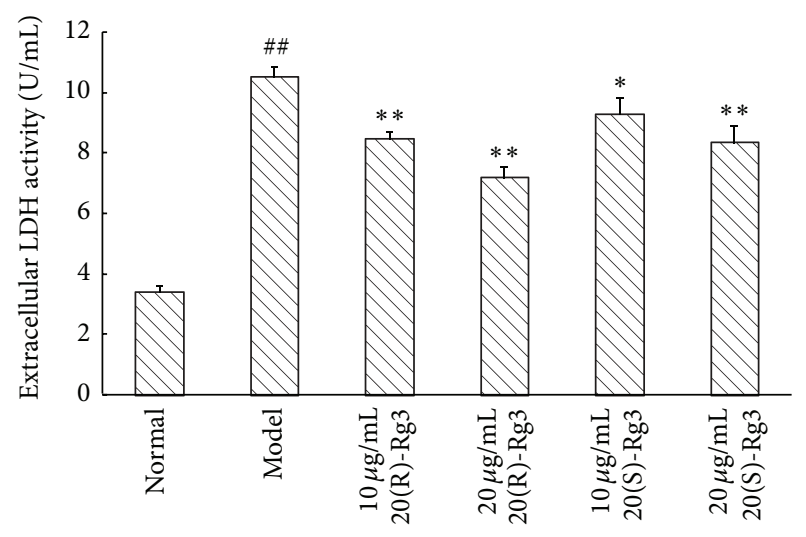

FIGURE 5: Protective effect of ginsenoside Rg3 on SK-N-SH cells by extracellular LDH assay. ${ }^{\# \#} P<0.01$ versus normal group, ${ }^{*} P<0.05$, and ${ }^{* *} P<0.01$ versus model group.

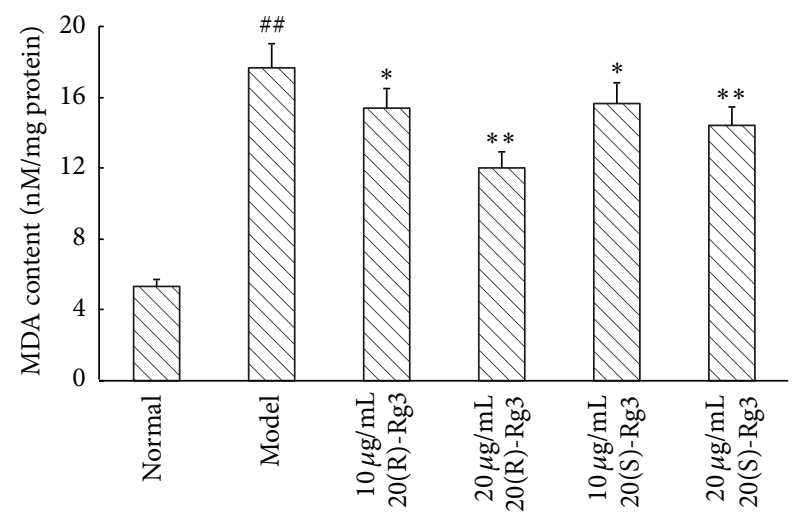

FIGURE 6: Ginsenoside Rg3 inhibited the MDA production in SK-NSH cells. ${ }^{\# \#} P<0.01$ versus normal group, ${ }^{*} P<0.05$, and ${ }^{* *} P<0.01$ versus model group.

Oxidative stress reflects an imbalance between the systemic manifestation of ROS and the ability to repair the resulting damage by the biological system or the intake of exogenous antioxidants [20]. Given oxidative stress, the intracellular ROS levels would sharply increase which had been confirmed by the $\mathrm{H}_{2} \mathrm{O}_{2}$ exposure in the present study (Figure 8). Ginsenoside Rg3 could obviously scavenge the ROS produced by $\mathrm{H}_{2} \mathrm{O}_{2}$. We investigated the intracellular ROS formation by fluorescent probe DCFH-DA. The results showed that compared with the $\mathrm{H}_{2} \mathrm{O}_{2}$ damaged group, 10 and $20 \mu \mathrm{g} / \mathrm{mL}$ of 20 (R) $-\mathrm{Rg} 3$ could decrease the ROS formation by $44.1 \%$ and $64.7 \%$, respectively, meanwhile 10 and $20 \mu \mathrm{g} / \mathrm{mL}$ of 20 (S) $-\mathrm{Rg} 3$ could decrease the ROS level by $29.2 \%$ and $51.3 \%$, respectively.

\section{Conclusions}

$\mathrm{H}_{2} \mathrm{O}_{2}$ exposure $(600 \mu \mathrm{M}$ for $4 \mathrm{~h})$ to human neuroblastoma SK-N-SH cells could significantly cause oxidative stress by reducing the intracellular SOD activity and promoting the MDA production and lead to further damage to cells. Ginsenoside Rg3, no matter 20(R)-Rg3 or 20(S)-Rg3, possesses 


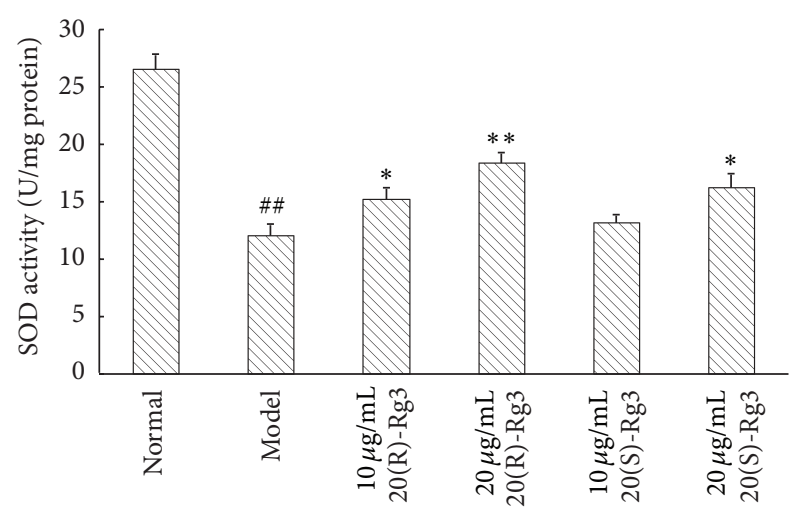

FIGURE 7: Ginsenoside Rg3 increased the SOD activity in SK-N-SH cells. ${ }^{\# \#} P<0.01$ versus normal group, ${ }^{*} P<0.05$, and ${ }^{* *} P<0.01$ versus model group.

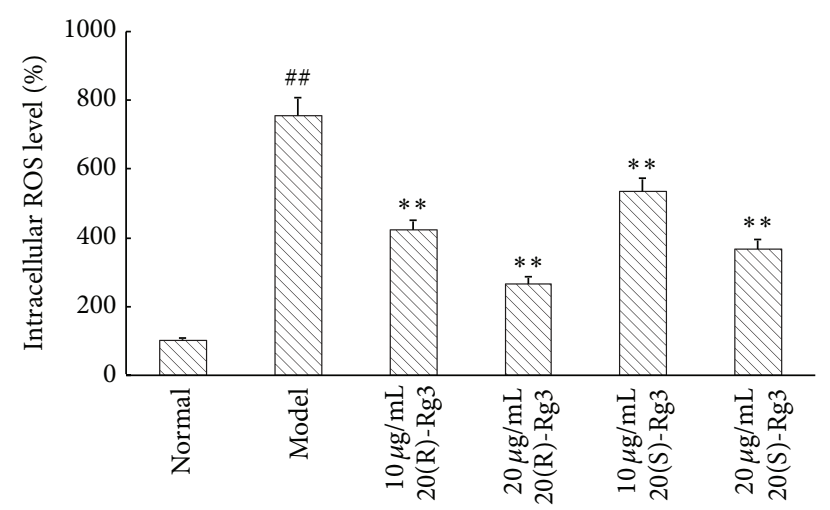

FIGURE 8: Ginsenoside Rg3 reduced the intracellular ROS formation in SK-N-SH cells. ${ }^{\# \#} P<0.01$ versus normal group and ${ }^{* *} P<0.01$ versus model group.

powerful ability of scavenging free radicals produced by $\mathrm{H}_{2} \mathrm{O}_{2}$. Thus, they exhibited the strong protective effects on SK-N-SH cells. In addition, we also found in the present study that 20(R)-Rg3 displayed better antioxidant activity than 20 (S)-Rg3 in vitro. These findings will benefit further research and application of ginsenoside $\mathrm{Rg} 3$ in neuroprotection.

\section{Conflict of Interests}

The authors declare that there is no conflict of interests regarding the publication of this paper.

\section{Acknowledgments}

This study was supported by the Natural Science Foundation of China (21372190) and the Excellent Young Scientists Award of Shandong Province, China (BS2012YY039).

\section{References}

[1] P. Y. K. Yue, N. K. Mak, Y. K. Cheng et al., "Pharmacogenomics and the Yin/Yang actions of ginseng: anti-tumor, angiomodulating and steroid-like activities of ginsenosides," Chinese Medicine, vol. 2, article 6, 2007.
[2] L. P. Christensen, "Ginsenosides: chemistry, biosynthesis, analysis, and potential health effects," Advances in Food and Nutrition Research, vol. 55, no. 1, pp. 1-99, 2008.

[3] Y. C. Kim, S. R. Kim, G. J. Markelonis, and T. H. Oh, "Ginsenosides $\mathrm{Rb} 1$ and $\mathrm{Rg} 3$ protect cultured rat cortical cells from glutamate-induced neurodegeneration," Journal of Neuroscience Research, vol. 53, no. 4, pp. 426-432, 1998.

[4] M. V. N. López, M. P. G.-S. Cuadrado, O. M. P. Ruiz-Poveda, A. M. V. Del Fresno, and M. E. C. Accame, "Neuroprotective effect of individual ginsenosides on astrocytes primary culture," Biochimica et Biophysica Acta-General Subjects, vol. 1770, no. 9, pp. 1308-1316, 2007.

[5] J.-H. Kim, S. Y. Cho, J.-H. Lee et al., "Neuroprotective effects of ginsenoside Rg3 against homocysteine-induced excitotoxicity in rat hippocampus," Brain Research, vol. 1136, no. 1, pp. 190199, 2007.

[6] S. Y. Nah, "Ginseng ginsenoside pharmacology in the nervous system: involvement in the regulation of ion channels and receptors," Frontiers in Physiology, vol. 5, article 98, 2014.

[7] M. Mochizuki, Y. C. Yoo, K. Matsuzawa et al., "Inhibitory effect of tumor metastasis in mice by saponins, ginsenoside- $\mathrm{Rb} 2$, 20(R)- and 20(S)-ginsenoside-Rg3, of red ginseng," Biological and Pharmaceutical Bulletin, vol. 18, no. 9, pp. 1197-1202, 1995.

[8] H.-H. Kwok, G.-L. Guo, J. K.-C. Lau et al., "Stereoisomers ginsenosides-20(S)-Rg3 and -20(R)-Rg3 differentially induce angiogenesis through peroxisome proliferator-activated receptor-gamma," Biochemical Pharmacology, vol. 83, no. 7, pp. 893-902, 2012.

[9] E.-A. Bae, M. J. Han, M.-K. Choo, S.-Y. Park, and D.-H. Kim, "Metabolism of 20(S)- and 20(R)-ginsenoside Rg3 by human intestinal bacteria and its relation to in vitro biological activities," Biological \& Pharmaceutical Bulletin, vol. 25, no. 1, pp. 58-63, 2002.

[10] Y. Wang, W. Zhao, X. Wu, and Y. Zhang, "Studies on the biotransformation of ginsenoside $\mathrm{Rg} 3$ by an active microorganism isolated from ginseng root soils in Changbai Mountain," Journal of Traditional Medicines, vol. 3, no. 5, 2008.

[11] J. Tian, F. Fu, M. Geng et al., "Neuroprotective effect of 20(S)ginsenoside Rg3 on cerebral ischemia in rats," Neuroscience Letters, vol. 374, no. 2, pp. 92-97, 2005.

[12] J. Tian, S. Zhang, G. Li, Z. Liu, and B. Xu, "20(S)-Ginsenoside $\mathrm{Rg} 3$, a neuroprotective agent, inhibits mitochondrial permeability transition pores in rat brain," Phytotherapy Research, vol. 23, no. 4, pp. 486-491, 2009.

[13] B. He, P. Chen, J. Yang et al., "Neuroprotective effect of 20(R)ginsenoside $\mathrm{Rg} 3$ against transient focal cerebral ischemia in rats," Neuroscience Letters, vol. 526, no. 2, pp. 106-111, 2012.

[14] J. W. Simpkins, P. S. Green, K. E. Gridley, M. Singh, N. C. De Fiebre, and G. Rajakumar, "Role of estrogen replacement therapy in memory enhancement and the prevention of neuronal loss associated with Alzheimer's disease," The American Journal of Medicine, vol. 103, no. 3, pp. 19-25, 1997.

[15] F. Ba, P. K. T. Pang, S. T. Davidge, and C. G. Benishin, "The neuroprotective effects of estrogen in SK-N-SH neuroblastoma cell cultures," Neurochemistry International, vol. 44, no. 6, pp. 401-411, 2004.

[16] P. Moongkarndi, C. Srisawat, P. Saetun et al., "Protective effect of mangosteen extract against $\beta$-amyloid-induced cytotoxicity, oxidative stress and altered proteome in SK-N-SH cells," Journal of Proteome Research, vol. 9, no. 5, pp. 2076-2086, 2010.

[17] G. Fotakis and J. A. Timbrell, "In vitro cytotoxicity assays: comparison of LDH, neutral red, MTT and protein assay in 
hepatoma cell lines following exposure to cadmium chloride," Toxicology Letters, vol. 160, no. 2, pp. 171-177, 2006.

[18] T. P. A. Devasagayam, K. K. Boloor, and T. Ramasarma, "Methods for estimating lipid peroxidation: an analysis of merits and demerits," Indian Journal of Biochemistry \& Biophysics, vol. 40, no. 5, pp. 300-308, 2003.

[19] J. M. Matés, "Effects of antioxidant enzymes in the molecular control of reactive oxygen species toxicology," Toxicology, vol. 153, no. 1-3, pp. 83-104, 2000.

[20] E. Birben, U. M. Sahiner, C. Sackesen, S. Erzurum, and O. Kalayci, "Oxidative stress and antioxidant defense," The World Allergy Organization Journal, vol. 5, no. 1, pp. 9-19, 2012. 

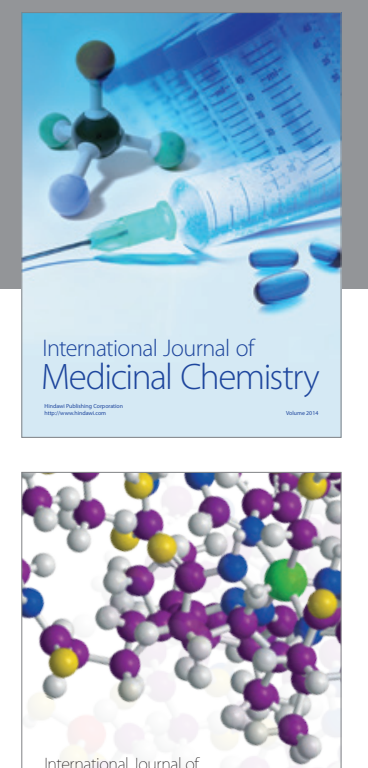

\section{Carbohydrate} Chemistry

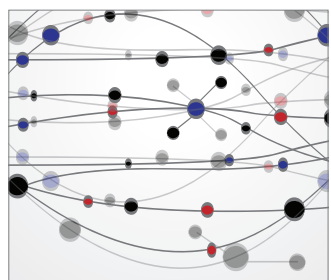

The Scientific World Journal
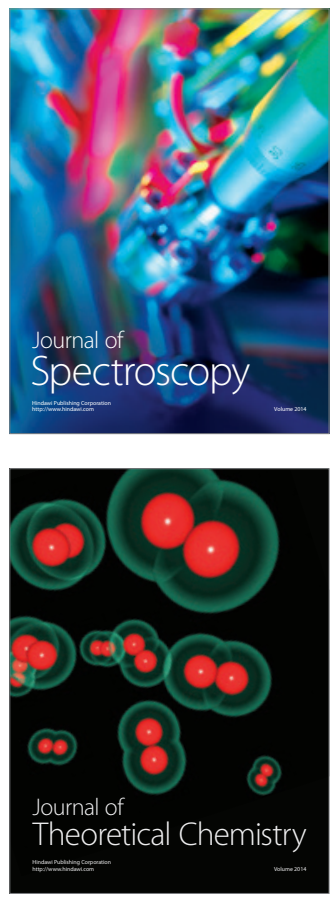
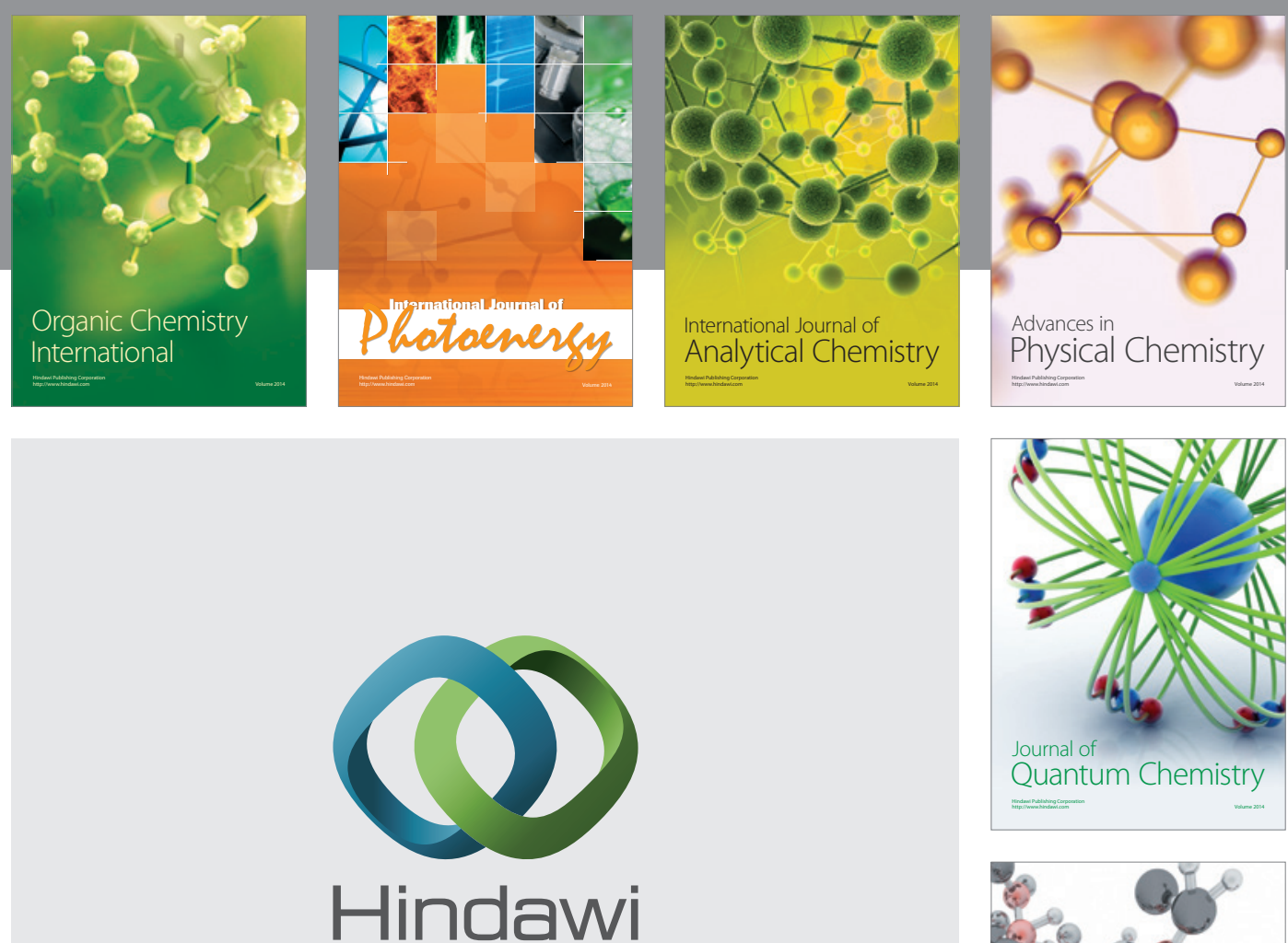

Submit your manuscripts at

http://www.hindawi.com

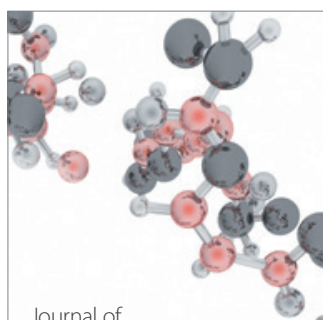

Analytical Methods

in Chemistry

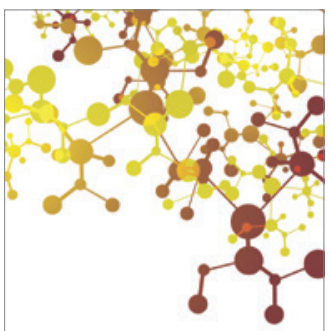

Journal of

Applied Chemistry

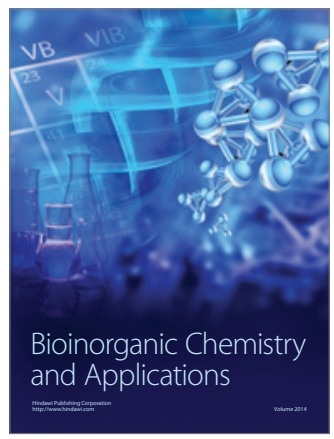

Inorganic Chemistry
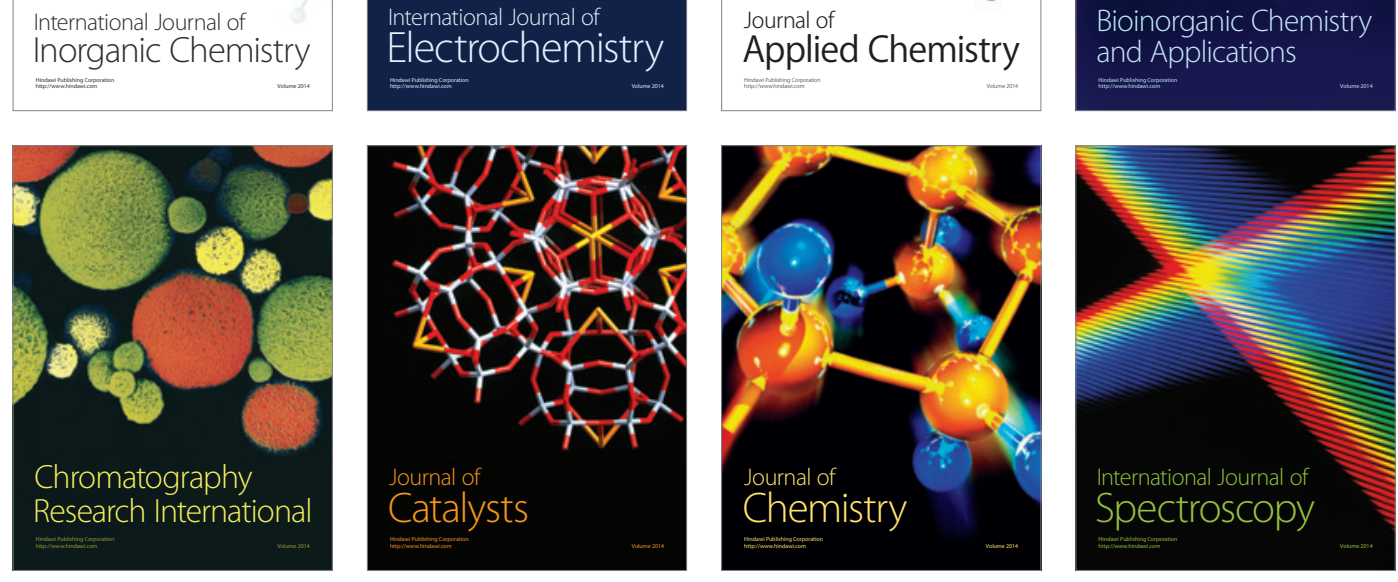